\title{
Studi Eksploratif Mengenai Karakteristik dan Faktor Pembentuk Identitas Etnik Sunda
}

\author{
Agus Abdul Rahman, Sarbini, Tarsono, Elis A. Fitriah, Agus Mulyana \\ UIN Sunan Gunung Djati, Jl. AH Nasution No. 105 Bandung \\ e-mail: agus.abdulrahman@uinsgd.ac.id
}

\begin{tabular}{|c|c|}
\hline Abstract / Abstrak & Keywords / Kata kunci \\
\hline $\begin{array}{l}\text { Jawa Barat is one of the provinces with strong cultural identity. Nowadays, } \\
\text { several districts in West Java seek to strengthen their cultural identity in various } \\
\text { ways. This study explores the characteristics and factors that shape the identity of } \\
\text { Sundanese. The study was conducted in one of the districts in West Java that are } \\
\text { intense in maintaining and developing Sundanese culture. Respondents consisted } \\
\text { of } 639 \text { students in seventeen schools. Data were collected using questionnaires } \\
\text { and interviews. The results show that the ethnic identity of the respondents was } \\
\text { above average. Most respondents have reached the "achieved" stage, which is } \\
\text { marked by strong exploration and commitment. Factors influencing the ethnic } \\
\text { identity of respondents include gender, parent education, and the use of } \\
\text { Sundanese as the native language. Sundanese ethnic characteristics are } \\
\text { mentioned by many respondents, among others, polite and polite, friendly or } \\
\text { "someah," solider and like mutual help, compassionate, sociable, and religious. }\end{array}$ & $\begin{array}{l}\text { Ethnic identity } \\
\text { Sundanese culture } \\
\text { Exploration } \\
\text { Commitment }\end{array}$ \\
\hline $\begin{array}{l}\text { Jawa Barat merupakan salah satu provinsi yang identitas budaya Sundanya sangat } \\
\text { kental. Dewasa ini, beberapa kabupaten di Jawa Barat berupaya memperkuat } \\
\text { identitas budayanya dengan berbagai cara. Penelitian ini mengeksplorasi } \\
\text { karakteristik dan faktor-faktor apa saja yang membentuk identitas etnik Sunda. } \\
\text { Penelitian dilakukan di salah satu kabupaten di Jawa Barat yang intens dalam } \\
\text { memelihara dan mengembangkan budaya Sunda. Responden terdiri dari } 639 \text { siswa } \\
\text { yang ada di tujuh belas sekolah. Data dikumpulkan dengan menggunakan angket } \\
\text { dan wawancara. Hasil penelitian menunjukkan bahwa identitas etnik responden } \\
\text { termasuk di atas rata-rata. Kebanyakan responden sudah mencapai tahapan } \\
\text { achieved, yang ditandai dengan eksplorasi dan komitmen yang sudah kuat. } \\
\text { Faktor-faktor yang berpengaruh terhadap identitas etnik responden antara lain } \\
\text { jenis kelamin, pendidikan orang tua, dan penggunaan bahasa Sunda sebagai } \\
\text { bahasa pengantar di rumah. Karakteristik etnik Sunda yang banyak disebutkan } \\
\text { oleh responden antara lain sopan dan santun, ramah atau someah, solider dan suka } \\
\text { gotong royong, penyayang, mudah bergaul, dan agamis. }\end{array}$ & $\begin{array}{l}\text { Identitas etnik } \\
\text { Budaya Sunda } \\
\text { Eksplorasi } \\
\text { Komitmen }\end{array}$ \\
\hline
\end{tabular}

\section{Pendahuluan}

Indonesia merupakan salah satu negara yang memiliki keragaman budaya yang sangat kaya. Indonesia kaya dengan suku bangsa, etnis, dan juga bahasa. Klaim tersebut tentu bukan tanpa dasar. Menurut data statistik yang dikeluarkan oleh Badan Pusat Statistik pada tahun 2010 menunjukan bahwa Indonesia memiliki 1.211 bahasa daerah, 300 kelompok etnis, dan 1.340 suku bangsa.

Menjelaskan perilaku, faktor budaya merupakan sesuatu yang sangat penting. Budaya memang seringkali disebut-sebut sebagai hasil karya manusia. Triandis (2007) menyebutkan bahwa budaya merupakan hasil interaksi adaptif antara orang-orang dengan lingkungannya, yang dibagi dan disosialisasikan dari satu generasi ke generasi lainnya. Namun, budaya pada gilirannya justru akan berpengaruh dan membentuk kepribadian dan perilaku manusia (Schultz \& Schultz, 2005). Rahman (2017) menyatakan bahwa hidup dalam suatu konteks budaya pasti memberikan efek terhadap pembentukan perilaku dan aspek psikologi.

Diantara budaya-budaya yang ada di Indonesia, budaya Sunda termasuk salah satu budaya yang cukup tua di Indonesia. Namun 
karena terpaan globalisasi dan modernisasi, budaya Sunda sedikit demi sedikit mengalami penurunan. Perkembangan teknologi komunikasi dan transportasi yang membuat interaksi antar etnik (interethnic relationship) semakin terbuka berakibat menurunnya pada karakter dan identitas etnik Sunda, khususnya pada remaja. Dewasa ini, budaya Sunda betul-betul sedang mengalami ujian. Jika kurang mampu merawat dan melestarikan, budaya Sunda boleh jadi akan tergerus oleh zaman dan hanya tinggal nama semata. Menyadari kondisi tersebut, beberapa pemerintahan kota dan kabupaten di Jawa Barat mencanangkan program-program penguatan budaya Sunda.

Penguatan identitas etnik memang perlu dilakukan. Hal ini karena penguatan identitas etnik berhubungan dengan tingginya perasaan sejahtera dan penyesuaian sosial (Phinney, 1989). Penelitian meta analisis terhadap 184 penelitian yang sudah pernah dilakukan menunjukkan bahwa identitas etnik berhubungan kuat dengan positive well-being dan penyesuaian diri (Smith \& Silva, 2011).

Bahasan mengenai identitas etnik sedang mengalami perkembangan (French, Seidman, Allen, \& Aber, 2006). Namun, beberapa penelitian sebelumnya mengenai pembentukan identitas etnik lebih fokus pada remaja. French, Seidman, Allen, dan Aber (2006) menyebutkan bahwa pembentukan identitas etnik memang cukup menonjol pada usia remaja. Hal itu mungkin karena pembentukan identitas etnik berhubungan dengan pembentukan identitas ego, yang itu terjadi pada usia remaja. Seperti halnya pembentukan identitas ego, pembentukan identitas etnik pun kemudian menjadi sangat penting bagi remaja.

Selain karena faktor perkembangan psikologisnya, pembentukan identitas etnik remaja menjadi penting karena perubahan konteks sosial yang mereka hadapi (Arnett, 2000). Frable (1997) menyebutkan bahwa identitas gender, ras, etnik, dan seksual merupakan sesuatu yang bersifat cair dan multidimensional serta merupakan produk kontruksi sosial. Oleh karena itu, orang yang hidup pada konteks sosial tertentu akan menghasilkan identitas etnik yang khas yang berbeda dengan orang lain yang hidup pada konteks sosial yang berbeda.

Dewasa ini, seiring dengan perkembangan dunia yang semakin mengglobal, remaja dihadapkan pada konteks sosial yang sangat beragam dan terus-menerus mengalami perubahan. Remaja saat ini dituntut untuk terus-menerus melakukan penyesuaian diri dengan lingkungan sosialnya. Remaja dituntut untuk selalu siap siaga menghadapi perubahan konteks sosial yang kadang sulit diprediksi. Mengenai bagaimana perubahan konteks sosial itu berpengaruh terhadap identitas remaja, penelitian-penelitian sebelumnya mengenai perkembangan identitas etnik remaja menunjukkan hasil yang beragam. Ada yang menyatakan bahwa identitas etnik remaja menguat (French, Seidman, Allen, \& Aber, 2006), menurun (Pahl \& Way, 2006), dan bahkan tidak ada perubahan (Fuligni, Kiang, Witkow, \& Baldelomar, 2008).

Memasuki lingkungan baru, seperti memasuki sekolah ataupun perguruan tinggi, seorang remaja berupaya mengkategorisasikan dirinya dengan konteks sosial yang paling dianggap sesuai (Tsai \& Fuligni, 2012). Penelitian Tsai dan Fuligni (2012) menunjukkan adanya beberapa faktor yang dapat membentuk identitas remaja, seperti jenis sekolah, status kependudukan, keterlibatan dalam kegiatan ekstrakurikuler, dan juga komposisi etnik yang ada di sekolah. Tsai dan Fuligni (2012) pun menyebutkan tiga domain yang dapat membentuk identitas etnik seseorang, yaitu ethnic labelling, ethnic search, dan ethnic belonging. Ethnic labelling menunjukkan pada afiliasi seseorang terhadap suatu kelompok etnik tertentu; ethnic search merupakan sejauhmana seseorang menggali makna dari keanggotaannya dalam suatu kelompok etnik tertentu; dan ethnic belonging merupakan sejauhmana seseorang memiliki perasaan positif dan bangga terhadap kelompok etniknya sendiri (Tsai \& Fuligni, 2012).

Identitas etnik menunjuk pada sejauhmana seorang individu mempersepsi dirinya sebagai 
bagian dari suatu kelompok etnik tertentu (Smith \& Silva, 2011) atau menunjuk pada perasaan diri seseorang mengenai keanggotaannya dalam suatu kelompok tertentu (Phinney, 1989). Identitas etnik adakalanya dibahas sebagai bagian dari perkembangan identitas diri yang ada dalam psikologi perkembangan, atau dibahas sebagai bagian dari perkembangan identitas sosial yang ada dalam psikologi sosial. Menurut Phinney, Horenczyk, Liebkind, dan Vedder (2001), identitas etnik memiliki beberapa aspek berikut: identifikasi diri, perasaan memiliki dan komitmen terhadap kelompok, perasaan berbagi nilai (sense of shared value), dan sikap terhadap kelompoknya sendiri.

Salah satu konsep mengenai identitas etnik adalah apa yang dikembangkan oleh Phinney pada tahun 1989. Berdasarkan teori status identitas Marcia, Phinney mengembangkan status identitas etnik dengan dua elemen penting yaitu eksplorasi dan komitmen. Berdasarkan kedua elemen tersebut, Phinney (1989) menyatakan bahwa identitas etnik berkembang melalui tiga tahapan. Pertama, tidak memiliki penilaian positif atau negatif terhadap kelompok etniknya (unexamined ethnic identity). Pada tahapan ini, seseorang tidak merasa identitas etniknya penting. Ia tidak melakukan eksplorasi ataupun komitmen. Kedua, melakukan pencarian mengenai makna menjadi anggota dari suatu kelompok etnik tertentu. Pada tahapan ini, seseorang melakukan explorasi, tapi belum menunjukkan komitmen (moratorium). Ketiga, mendapatkan kejelasan mengenai makna keanggotaannya dalam kelompok etnik tertentu (achieved ethnic identity). Pada tahapan ini, seseorang sudah melakukan eksplorasi dan komitmen.

\section{Metode}

Metode penelitian ini termasuk metode survey, yang bertujuan untuk mendapatkan gambaran mengenai identitas etnik remaja dan faktor yang berhubungan dengan identitas etnik tersebut di suatu kabupaten di Jawa Barat. Pengumpulan data dilakukan dengan meng- gunakan metode questionnaire, skala, dan wawancara. Questionnaire terdiri dari pertanyaan terbuka dan tertutup mengenai identitas etnik, skala terdiri dari berbagai item yang disusun berdasarkan identitas etnik dari Phinney, dan wawancara dilakukan secara sistematis yang tujuannya untuk mendapatkan informasi deskriptif yang tidak dapat diperoleh oleh metode questionnaire dan skala. Subjek penelitian ini adalah siswa sekolah menengah umum (SMU) yang ada di 17 sekolah yang ada di 17 kecamatan yang sedang diteliti. Pemilihan sekolah dan kecamatan sebagai sampel penelitian dilakukan secara random. Subjek penelitian terdiri dari 639 siswa. Subjek yang berjenis kelamin laki-laki berjumlah 202 orang (31.6 persen) dan subjek yang berjenis kelamin perempuan berjumlah 437 siswa (68.4 persen). Data dianalisis dengan menggunakan statistik deskriptif dan inferensial, serta analisis isi.

\section{Hasil}

\section{Kategori Identitas Etnik Responden}

Membandingkan antara mean hipotetik (30.00) dan mean empirik (38.62), diperoleh kesimpulan bahwa identitas etnik Sunda responden termasuk di atas rata-rata. Kategori tersebut sama di semua sekolah yang menjadi responden penelitian. Walaupun demikian, terdapat 19.7 persen (127 responden) yang kategori identitas etniknya lemah, dan 3 persen (20 responden) kategori identitas etniknya sangat lemah. Hal ini boleh jadi berhubungan dengan komposisi responden yang lebih banyak perempuan (437 orang atau 68.4 persen) daripada laki-laki (202 orang atau 31.6 persen). Komposisi jenis kelamin responden yang lebih banyak perempuan diduga berhubungan dengan kuatnya rata-rata skor identitas etnik responden. Penelitian ini menunjukkan bahwa terdapat perbedaan identitas etnik antara responden yang berjenis kelamin laki-laki dan perempuan, $t$ $(627)=-2.264, p=.024$. Perempuan $(\mathrm{M}=38.89$, $\mathrm{SD}=4.13)$ memiliki identitas etnik yang lebih kuat dibanding laki-laki $(\mathrm{M}=38.06, \mathrm{SD}=4.50)$. 


\section{Komitmen dan Ekplorasi Responden}

Berdasarkan analisis terhadap dua aspek identitas etnik, baik komitmen ataupun eksplorasi menunjukkkan bahwa 44.2 persen (283 responden) sudah mencapai tahapan achieved atau sudah menunjukkan eksplorasi dan komitmen yang kuat terhadap etniknya, dan 5.4 persen (35 responden) yang belum menunjukkan eksplorasi dan komitmen terhadap etnik tertentu.

Ini artinya, walaupun sudah hampir separuh responden menunjukkan komitmen dan eksplorasi yang tinggi, namun lebih dari dua puluh persen responden masih menunjukkan komitmen dan eksplorasi yang rendah. Hal ini tentu harus menjadi perhatian pemerintah setempat untuk membuat program-program yang dapat meningkatkan kedua aspek identitas etnik tersebut.

\section{Faktor Pembentuk Identitas Etnik Sunda}

Selain faktor jenis kelamin yang secara empirik terbukti berpengaruh terhadap identitas etnik, faktor lain yang berpengaruh adalah penggunaan bahasa Sunda dalam kehidupan sehari-hari dan juga latar belakang pendidikan orang tua.

Penelitian ini menunjukkan bahwa terdapat perbedaan identitas etnik antara responden yang menggunakan bahasa Sunda, bahasa Indonesia, dan bahasa lainnya, baik di rumah $\mathrm{F}(2)=34.71$, $p<.001$, maupun di masyarakat $\mathrm{F}(2)=9.642, p$ $<.001$. Data menunjukkan bahwa responden yang menggunakan bahasa Sunda sebagai bahasa pengantar di rumahnya memiliki identitas etnik yang lebih kuat $(\mathrm{M}=39.34, \mathrm{SD}=$ 3.91) daripada responden yang memakai bahasa Indonesia $(\mathrm{M}=37.60, \mathrm{SD}=4.69)$, atau bahasa lainnya $(M=37.84, S D=3.57)$. Demikian juga, responden yang menggunakan bahasa Sunda sebagai bahasa pengantar di masyarakat memiliki identitas etnik yang lebih kuat $(\mathrm{M}=39.353, \mathrm{SD}=3.77)$, daripada responden yang memakai bahasa Indonesia $(\mathrm{M}=36.10$, $\mathrm{SD}=5.06)$, atau bahasa lainnya $(\mathrm{M}=36.58$, $\mathrm{SD}=3.98)$.

Selain itu, penelitian ini juga menunjukkan bahwa terdapat perbedaan identitas etnik

Tabel 1. Identitas etnik berdasarkan pendidikan ayah

\begin{tabular}{lllll}
\hline & $\mathrm{N}$ & Mean & Std. Deviation & Std. Error \\
\hline SD & 249 & 39.6707 & 3.74865 & .23756 \\
SMP & 113 & 39.0442 & 4.07166 & .38303 \\
SMU & 206 & 37.7670 & 4.52571 & .31532 \\
Diploma & 17 & 35.6471 & 5.20746 & 1.26299 \\
S1/S2/S3 & 54 & 37.1296 & 4.15295 & .56515 \\
Total & 639 & 38.6244 & 4.26472 & .16871 \\
\hline
\end{tabular}

Tabel 2. Identitas etnik berdasarkan pendidikan ibu

\begin{tabular}{lllll}
\hline & $\mathrm{N}$ & Mean & Std. Deviation & Std. Error \\
\hline SD & 312 & 39.6090 & 3.72715 & .21101 \\
SMP & 125 & 38.3120 & 4.15315 & .37147 \\
SMU & 145 & 37.6276 & 4.68885 & .38939 \\
Diploma & 22 & 35.6818 & 4.35766 & .92906 \\
S1/S2/S3 & 35 & 36.9429 & 4.94644 & .83610 \\
Total & 639 & 38.6244 & 4.26472 & .16871 \\
\hline
\end{tabular}

Tabel 3. Analisis terhadap aspek-aspek identitas etnik responden

\begin{tabular}{ccccc}
\hline & & \multicolumn{2}{c}{ Komitmen } & \multirow{2}{*}{ Total } \\
\hline \multirow{2}{*}{ Eksplorasi } & Tinggi & $283(44.2 \%)$ & $35(5.4 \%)$ & 318 \\
& Rendah & $179(28 \%)$ & $142(22.2 \%)$ & 321 \\
\multicolumn{2}{c}{ TOTAL } & 462 & 177 & 639 \\
\hline
\end{tabular}


responden berdasarkan pendidikan orang tua, baik pendidikan ayah, $\mathrm{F}(4)=10.412, p<.001$, maupun pendidikan ibu $\mathrm{F}(4)=10.924, p<.001$. Data menunjukkan bahwa pendidikan orang tua berhubungan negatif dengan identitas etnik remaja. Responden yang berasal dari orang tua berpendidikan rendah cenderung memiliki identitas etnik yang lebih kuat dibanding remaja yang berasal dari orang tua yang berpendidikan tinggi. Tabel 1 dan 2 menunjukkan bahwa responden yang ayah $(\mathrm{M}=39.67, \mathrm{SD}=3.75)$ atau ibunya $(\mathrm{M}=39.60, \quad \mathrm{SD}=3.7) \quad$ berpendidikan sekolah dasar memiliki identitas etnik yang paling kuat dibanding yang lainnya.

\section{Karakteristik Identitas Etnik Sunda}

Karakteristik identitas etnik Sunda diperoleh dengan menggunakan pertanyaan terbuka "Sebutkan tiga karakteristik yang menjadi ciri khas orang Sunda?" Isi jawaban dari responden dianalisis dan dikategorikan menjadi beberapa kategori.

Terdapat delapan karakteristik identitas etnik Sunda yang paling banyak disebutkan oleh responden, yaitu: sopan dan santun, ramah atau someah, solider dan suka gotong royong, mudah bergaul, agamis, kreatif dan rajin, toleran, serta teguh pendirian.

Tabel 4. Karakteristik etnik Sunda menurut responden

\begin{tabular}{clc}
\hline No & \multicolumn{1}{c}{ Karakteristik } & Frekuensi \\
\hline 1 & Sopan santun & 198 \\
2 & Ramah/Someah & 168 \\
& Kebersamaan/Gotong & 46 \\
3 & royong/Solidaritas & \\
4 & Lembut dan penyayang & 29 \\
5 & Mudah bergaul & 18 \\
6 & Agamis & 14 \\
7 & Kreatif/rajin & 11 \\
8 & Toleran & 8 \\
\hline
\end{tabular}

\section{Diskusi}

Hasil penelitian menunjukkan bahwa sebagian besar identitas etnik responden termasuk kategori kuat. Artinya, responden menunjukan penghayatan yang baik terhadap nilai-nilai kesudaan. Orang yang menghayati suatu nilai, termasuk nilai-nilai kesundaan seperti cageur, bageur, bener, singer dan pinter diduga akan menunjukkan nilai-nilai kesundaan tersebut pada kehidupan sehari-hari.

Responden pun menyadari dan mengetahui bahwa karakteristik utama dari orang Sunda adalah perilaku sopan santun seperti yang ditampilkan di Tabel 4. Selain sopan santun, perilaku ramah pun menjadi karakteristik kedua terbesar yang harus dimiliki oleh orang Sunda sehingga dengan pengetahuan yang dimiliki seharusnya mereka dapat mengaplikasikannya dalam perilaku mereka sehari-hari, walaupun hal tersebut masih sangat dipengaruhi oleh faktor-faktor lainnya.

Penghayatan etnik Sunda yang kuat, didukung pula oleh komitmen yang tinggi terhadap etniknya. Seperti yang dijelaskan oleh Phinney dan Ong (2007) bahwa komitmen atau sense of belonging bisa menjadi komponen penting dalam identitas etnik. Ashmore, Deaux, McLaughlin-Volpe (2004) menjelaskan bahwa attachment atau komitmen afeksi merupakan komponen kunci dalam identitas kelompok. Seseorang yang memiliki kedekatan emosional terhadap etnik maka akan berusaha untuk menjaga etnik mereka. Hal inilah yang dapat membuat orang Sunda tetap berusaha untuk menjaga Sunda tetap utuh dan akan menampilkan perilaku yang akan menjaga nama baik etnik Sunda itu sendiri.

Selain memiliki komitmen yang tergolong tinggi terhadap etnik mereka pun memiliki kesediaan untuk melakukan eksplorasi yang juga tinggi seperti yang dijelaskan di Tabel 3. Hal ini menggambarkan bagaimana rasa memiliki yang tinggi terhadap Sunda disertai dengan upaya yang juga tinggi dalam mencari informasi mengenai etnik Sunda. Eksplorasi sendiri diartikan sebagai usaha untuk mencari informasi dan pengalaman yang relevan berkaitan dengan etniknya (Phinney \& Ong, 2007). Dengan kesediaan untuk mengeksplorasi budaya Sunda maka responden akan berusaha 
untuk mencari informasi lebih lanjut dalam rangka mendapatkan pemahaman yang lebih utuh mengenai etnik Sunda.

Dengan memiliki komitmen dan eksplorasi yang tinggi maka mereka sudah mencapai tahapan achieved. Hal ini dapat diartikan bahwa responden sudah memiliki komitmen akan penghayatan kebersamaan dengan etnik Sunda yang terjadi berdasarkan pada pengetahuan dan pengertian yang dimiliki sehingga mereka dapat memiliki pemahaman melalui suatu eksplorasi aktif tentang latar belakang dari etnik Sunda. Ketika memiliki hal tersebut, para siswa akan merasakan perasaan aman dengan diri sendiri sebagai bagian dari anggota etnik Sunda. Mereka merasa nyaman menjadi bagian dari etnik Sunda dengan penghayatan kenyamanan yang tentu saja berbeda dari masing-masing individunya. Terlebih lagi perbedaan jenis kelamin pun memberikan dampak terhadap pembentukan identitas etnik dimana perempuan memiliki identitas etnik yang lebih tinggi dibandingkan dengan laki-laki seperti yang dijelaskan di Tabel 3. Temuan empirik ini mengkonfirmasi penelitian sebelumya yang menunjukkan bahwa dibanding laki-laki, perempuan memiliki identitas etnik yang lebih kuat (Warikoo, 2006).

Berkaitan dengan penguatan identitas etnik, penggunaan bahasa Sunda sebagai bahasa pengantar di keluarga dan di masyarakat, merupakan salah satu faktor yang membuat identitas etnik responden menjadi kuat. Selain itu, faktor pendidikan orang tua pun menjadi salah satu faktor penting dalam menguatkan identitas etnik Sunda pada responden. Berdasarkan Tabel 1 dan Tabel 2 dapat dilihat bahwa orang tua dengan latar belakang pendidikan SD baik pada ayah maupun ibu memiliki peran yang lebih besar dalam membentuk identitas etnik pada responden daripada orang tua dengan latar belakang pendidikan lainnya. Hal ini dapat menjadi salah satu gambaran bahwa untuk meningkatkan identitas etnik Sunda dapat menyasar pada orang tua dengan latar belakang pendidikan yang tinggi.
Berdasarkan infomasi dari responden yang merupakan siswa SMA/SMK terlihat bahwa pada dasarnya pihak sekolah telah melakukan upaya untuk menguatkan identitas etnik siswanya dengan melakukan program-program dalam kegiatan belajar mengajar berdasarkan program yang dicanangkan oleh Bupati. Program ini pun bisa menjadi salah satu faktor yang menguatkan identitas etnik Sunda pada responden sehingga hasil yang didapat dari penelitian ini adalah identitas etnik Sunda pada siswa/siswi SMA/SMK tergolong kuat dimana $51 \%$ respondennya memiliki identitas etnik yang kuat.

\section{Simpulan}

Penelitian ini menyimpulkan beberapa hal antara lain

1. Identitas etnik responden termasuk di atas rata-rata, dan umumnya sudah mencapai tahapan achieved.

2. Identitas etnik responden yang berjenis kelamin perempuan lebih kuat dibandingkan responden berjenis kelamin laki-laki. Hal ini mendukung hasil penelitian sebelumnya.

3. Identitas etnik responden berhubungan dengan penggunaan bahasa Sunda sebagai bahasa pengantar baik di rumah ataupun masyarakat. Responden yang menggunakan bahasa Sunda sebagai pengantar berhubungan dengan kuatnya identitas etnik.

4. Identitas etnik responden berhubungan dengan tingkat pendidikan orang tua. Pendidikan orang tua yang rendah berhubungan dengan kuatnya identitas etnik responden.

5. Karakteristik orang Sunda menurut persepsi responden adalah sopan santun, ramah/someah, suka bergotong royong, lembut dan penyayang, mudah bergaul, agamis, kreatif/rajin, dan toleran.

\section{Saran}

Berdasarkan hasil penelitian ini, ada beberapa saran yang bisa disampaikan, yaitu:

1. Program-program penguatan identitas etnik Sunda perlu dilanjutkan dan ditingkatkan. 
2. Penguatan identitas etnik sunda sebaiknya lebih intens lagi terutama terhadap masyarakat yang berjenis kelamin laki-laki, dan juga masyarakat yang berpendidikan tinggi.

3. Menggalakkan penggunaan bahasa Sunda sebagai bahasa pengantar di rumah, kantor, ataupun masyarakat akan cukup membantu dalam menguatkan identitas etnik Sunda.

4. Penelitian-penelitian serupa dengan topik yang berbeda sebaiknya dilakukan di kabupaten-kabupaten lainnya.

5. Penelitian mengenai karakteristik orang Sunda sebaiknya tidak cukup hanya menggunakan responden dari masyarakat Sunda sendiri. Penting juga untuk mengetahui bagaimana karakteristik masyarakat Sunda menurut kelompok etnis lainnya (outgroup).

6. Penelitian berikutnya bisa dilakukan dengan menggunakan metode penelitian yang lebih mendalam, baik kualitatif maupun kuantitatif.

\section{Referensi}

Arnett, J.J. (2000). Emerging adulthood: A theory of development from the late teen through twenties. American Psychologist, 55, 469-480

Ashmore, R. D., Deaux, K., \& McLaughlinVolpe, T. (2004). An organizing framework for collective identity: Articulation and significance of multidimensionality. Psychological Bulletin, 130, 80-114.

Frable, D.E.S (1997). Gender, racial, ethnic, sexual, and class identites. Anиual Review of Psychology. 48, 1-18

French, S. E., Seidman, E., Allen, L., \& Aber, J. L. (2006). The development of ethnic identity during adolescence. Developmental Psychology, 42, 1-10.

Fuligni, A.J., Kiang, L., Witkow, M.R , \& Baldelomar, O. (2008). Stability and change in ethnic labeling among youth from Asian and Latin American immigrant families. Child Development, $\quad 79, \quad 944-956$. doi:10.1111/j.1467-8624.2008.01169.x

Pahl, K., \& Way, N. (2006). Longitudinal trajectories of ethnic identity among urban Black and Latino adolescents. Child Development, 77, 1403-1415. doi:10.1111/j.1467-8624.2006.00943.x

Phinney, J. S. (1989). Stages of ethnic identity development in minority group adolescents. Journal of Early Adolescence, 9, 34-49.

Phinney, J.S., Horenczyk, G., Liebkind, K., \& Vedder, P., (2001). Ethnic identity, immigration, and well-being: An interactional perspective. Journal of Social Issues, 57(3), 493-510

Phinney, J.S., \& Ong, A.D., (2007). Conceptualization and measurement of ethnic identity: Current status and future directions. Journal of Counseling Psychology, 54, 271-281.

Rahman, A.A. (2017). Sejarah psikologi: dari klasik hingga modern. Depok: Rajagrafindo Press.

Schultz, D.P. \& Schultz, S.E. (2005). Theories of personality. Belmont, CA: Wardsworth Cengage Learning.

Smith, T.B \& Silva, L. (2011). Ethnic identity and personal well-being of people of color: A meta-analysis. Journal of Counseling Psychology, 58(1), 42-60.

Triandis, H. C. (2007). Culture and psychology: A history of the study of their relationship. In S. Kitayama \& D. Cohen (Eds.), Handbook of cultural psychology (pp. 59-76). New York: Guilford Press.

Tsai, K.M., \& Fuligni, A.J. (2012). Change in Ethnic Identity Across the College 
STUDI EKSPLORATIF MENGENAI KARAKTERISTIK DAN FAKTOR PEMBENTUK IDENTITAS ETNIK SUNDA

Transition. Developmental Psychology, 48(1), 56-64.

Warikoo, N. (2006). Gender and ethnic identity among second-generation Indo-Caribbeans. Journal Ethnic and Racial Studies, 28(5), 803-831. doi.org/10.1080/01419870500158752 